\title{
Structural repair of decayed old timber end beams
}

\author{
J.M. Branco \\ ISISE, Dept. of Civil Engineering, University of Minho Guimarães, Portugal \\ F. Ferreira \\ AOF - Augusto de Oliveira Ferreira \& CA Lda, Braga, Portugal
}

\begin{abstract}
Timber end-beams represent portions with high risk of degradation due to biotic agents like rot fungi and insect attacks. Different repair techniques are available, with distinctive level of intrusion, but the substitution of the damaged part with a solid wood prosthesis is a methodology well accepted. The connection of the prosthesis to the original member can use screws, binding strips, stirrups and glued-in rods. Despite it is possible to find different case studies in literature, no study is known for the case of maritime pine beams and prosthesis connected with glued-in steel rods. This works intends to fill this gap by presenting an experimental campaign aimed to evaluate a technique to repair timber end beams through the use of wood prosthesis connected to the original element by glued-in steel rods. For comparison purposes, the addition of new timber elements connected by screws is also evaluated as its represents a current practice in Portugal.
\end{abstract}

\section{INTRODUCTION}

The importance of the preservation of timber structures of historical and cultural interest has increased its importance in the recent years, as can be attested by different guidance for intervention issued by national or international technical committees (e.g. international ICOMOS IWC, RILEM RC 215 AST, RILEM TC 245 RTE and Italian UNI-NORMAL WG20). These documents recognize the importance of timber structures from all periods as part of the cultural heritage, whereas some standards recommend the assessment and the conservation of existing timber structures also for technical and structural reasons: for instance, since 2003 the Italian technical codes indicate the saving of timber diaphragms as a strategic issue in the reduction of seismic vulnerability of existing buildings, do not supporting the practice of substituting these structural elements with heavier and more invasive diaphragms, such as concrete slabs.

The assessment of existing timber structures requires, and relies, on the determination of the mechanical properties of the individual timber members as well as the behaviour of joints and, of structural system effects. In existing timber structures, the first step towards the safety assessment is the evaluation of the actual mechanical properties of the material. Despite significant effort in the development of non-destructive testing, true strength of a timber member can only be directly determined in a destructive test, which is often unacceptable in the case of historic buildings and other existing timber structures. In practice, it is the lack of knowledge about the material and its structural behaviour that normally leads to the replacement of existing wood structures, instead of their retrofitting.

In the specific case of wooden elements, it is well known that end-beams represent portions with high risk of degradation due to biotic agents (rot fungi and insect attacks). In fact, when a high level of humidity is present in masonry (e.g., due to infiltration for disconnections in roofing) and the adsorbed moisture cannot be evaporated because of lacking in ventilation, the suitable 
conditions for biotic attacks are established, and therefore degradation of end-beams can be expected (see Figure 1). This fact is well known among structural restorers and engineers familiar with timber. The first considerations about the effects of moisture content onto the end-beams were due to Vitruvio (Barbaro, 1997), whereas the suggestion of preparing aerated supports for hosting beam heads were firstly attributable to Leon Battista Alberti (Portuguese et al., 1966).
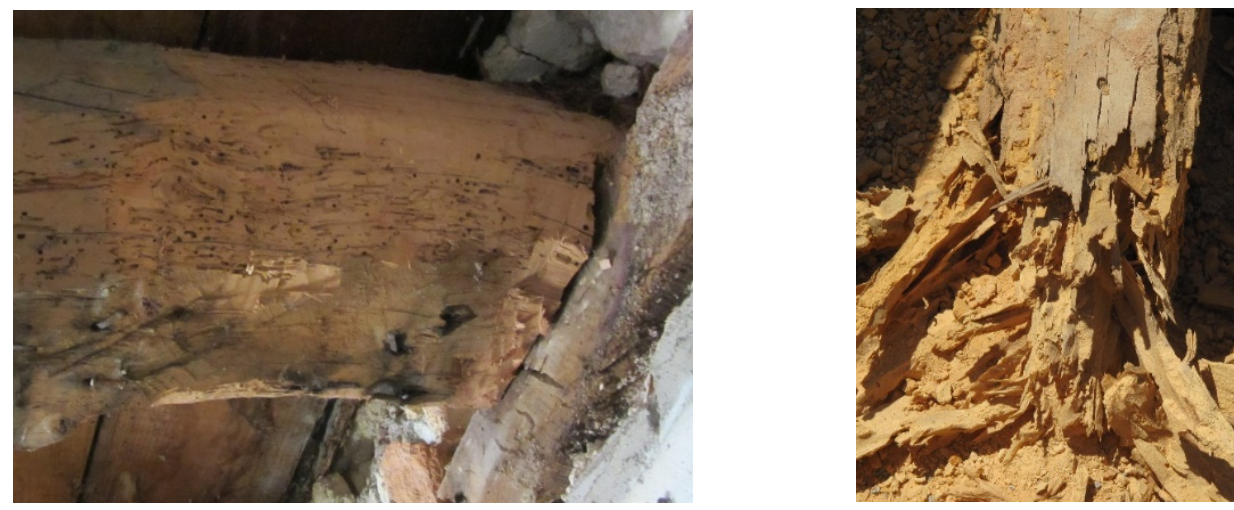

Figure 1. Examples of decayed old timber end beams.

Nowadays, several examples of techniques and methods can be found in literature for the repair and reinforcement of timber end beams (Tampone, 1996; Arriaga et al., 2002; Appleton 2003). In fact, since the early seventies, diverse companies have purposed materials and techniques to repair decayed timber elements. It is possible to identify two distinct groups of techniques: one using wood based materials or steel elements and the other based on the so-called new materials as fiber reinforced polymers (FRP) and resins. Different levels of intrusion can be identified in the case studies reported in literature but all interventions considers the repair of individual structural elements as a mean to restore the support that has been lost. The simplest intervention consists in the substitution of the decayed part by a new element which can be made of wood (Figure 2a) or in steel (Figure 2b). Other approaches regards the substitution of the damaged part with a solid wood prosthesis connected to the remaining part of the element using glued-in plates (Figure $2 \mathrm{c}$ ) or rods (Figure $2 \mathrm{~d}$ ).

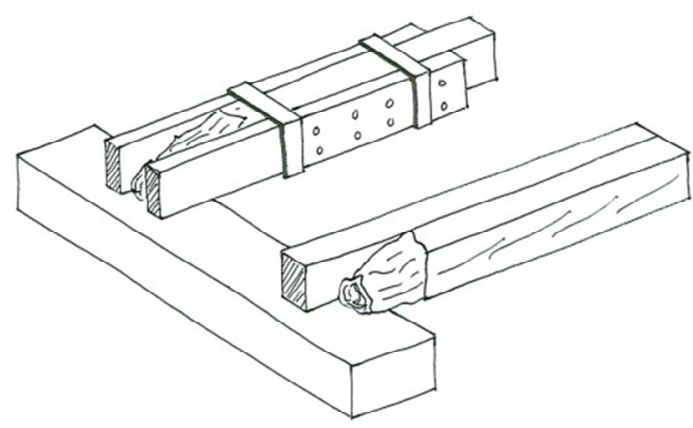

a) New wood elements
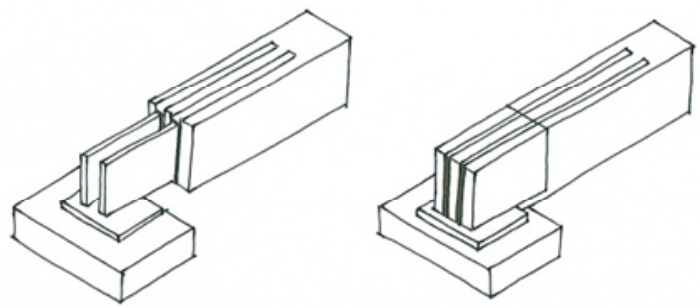

c) Glued-in plates connecting the prosthesis

Figure 2. Examples of possible repairing techniques based on the addition of new elements or wood prosthesis.

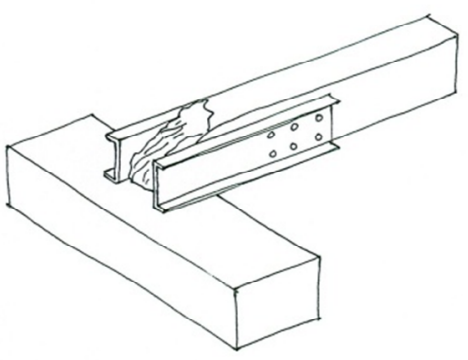

b) New steel elements

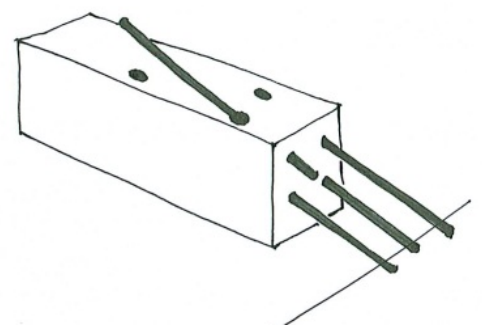

d) Glued-in rods connecting the prosthesis 
When the aesthetic value is not important, the connection of the prosthesis can be external, using nailed of screwed plates. However, usually, prosthesis are connected to the undamaged part of the element through glued-in plates or rods. Plates and rods can be in FRP (glass, carbon and aramid) but the steel ones are the more appreciated due to their reduced cost. The use of wood prosthesis become well accepted mainly due to their low intrusion level, simplicity and good aesthetic value.

The design of the repair has followed and approach based on the basic construction rules, probable simplistic but evident successful. For example, that one used for the Beta-System considered a strain distribution in repaired beam similar to that one of sound wood, and moreover imposed that the Moment of Resistance of the sound timber was equal to that one of rods used for the intervention. In such a way the total area of rods could be calculated. The length of anchorage was calculated simply basing on the resin-to-rods allowable bond stress, and on shear strength of sound timber (so, rigid bond between resin and wood was assumed as related to the design safety value of shear strength for wood). Apart from these empirical approaches, based on the allowable stresses, the adoption since 1994 of Eurocode 5 (EN 1995-1-1:2004) changed the way to handle the design approach of this kind of interventions, and nowadays in several countries specific codes exist that allow executing a proper design. The common approach is substantially similar to that described in the former standard ENV 1995-2:1997, and not appearing in the current version of EN 1995-2:2008. European Countries have obviated to this normative deficiency through national documents unfortunately, Portugal has not been the case. Therefore, experimental works are needed to evaluate the reliability in the load predicting ability of the design approach proposed by others national documents (e.g. the Italian CNR-DT 206/2007) to the Portuguese case, in terms of wood species, repairing materials, type of damage, etc.

This works try to fill this gap by presenting an experimental campaign aimed to evaluate a technique to repair timber end beams through the use of wood prosthesis connected to the original element by glued-in steel rods. For comparison purposes, the addition of new timber elements connected by screws is also evaluated as its represents a current practice in Portugal.

\section{EXPERIMENTAL PROGRAM}

An experimental campaign composed by full-scale four point bending tests according to EN 408:2010 was defined to evaluate the repair of decayed timber end beams. The main objective is to evaluate the use of wood prosthesis connected to the original element by glued-in steel rods. However, for comparison purposes, and because its represents the current practice in Portugal, the use of new timber elements connected by screws to the original elements was also evaluate. A total of 15 specimens were tested. Nine simulating the use of wood prosthesis and six using new timber elements to restore the decayed end beam. In this case, the use of one single element or the use of two new elements was evaluated. For the prosthesis, glued-in steel rods were used and the geometry of the connections between the prosthesis and the original element was studied. Namely, a vertical, diagonal and mixed geometries of the joint were considered. Table 1 summarizes the tested specimens and the main variable evaluated.

Table 1. Summary of the experimental campaign.

\begin{tabular}{|c|c|c|c|c|}
\hline Series & Specimens & \multicolumn{2}{|r|}{ Technique } & Joint geometry \\
\hline $\mathrm{O}$ & 3 & \multirow{2}{*}{$\begin{array}{l}\text { Use of a new } \\
\text { timber element }\end{array}$} & One element screwed in single shear & Vertical \\
\hline $\mathrm{T}$ & 3 & & Two elements screwed in double shear & Vertical \\
\hline GV & 3 & \multirow{3}{*}{$\begin{array}{l}\text { Timber pros- } \\
\text { thesis }\end{array}$} & \multirow{3}{*}{ Glued-in steel rods } & Vertical \\
\hline GD & 3 & & & Diagonal \\
\hline GM & 3 & & & Mixed \\
\hline
\end{tabular}

\subsection{Materials and specimens}

All specimens were made of maritime pine (Pinus pinaster) graded according to NP 4305:1995 as belonging to the quality class $\mathrm{E}$, corresponding to the $\mathrm{C} 18$ strength class defined by 
EN 338:2003 in accordance with the establish by EN 1912:2004. Two types of screws manufactured by Rothoblaas ${ }^{\circledR}$ have been used. HBS $6 \times 140$ in the case of the specimens $\mathrm{O}$ and HBS $8 \times 180$ for the specimens identified as T. To connect the timber prosthesis with the original elements, glued-in steel rods were used. Rods with a diameter of $10 \mathrm{~mm}$ and a length of $140 \mathrm{~mm}$ made of steel of grade 5.5 have been glued using the Mapewood $\AA$ Gel 120 glue.

The specimens were evaluated through four-point bending tests according to EN 408:2010 with a cross-section of $100 \times 150 \mathrm{~mm}^{2}$ and a free span of $2700 \mathrm{~mm}$. The prosthesis used had the same cross-section of the original element $\left(100 \times 150 \mathrm{~mm}^{2}\right)$. The distinction between the specimens defined to evaluate this technique is made by the geometry of the joint (cutting). The easiest cut is the vertical despite the diagonal is the one more used in practice. However, based on some previous findings (Pizzo et al., 2013), a mixed geometry, comprising vertical and diagonal cuts was proposed (Figure 3). In all cases, the anchorage length of the steel rod was fixed equal to $80 \mathrm{~mm}$.

In the case of the repair technique based on the use of new timber elements, the effective crosssection was reestablish by one new element of $100 \times 150 \mathrm{~mm}^{2}$ (Figure 4) or two new elements of $50 \times 150 \mathrm{~mm}^{2}$ (Figure 5), in the case of specimens $\mathrm{O}$ and $\mathrm{T}$, respectively.

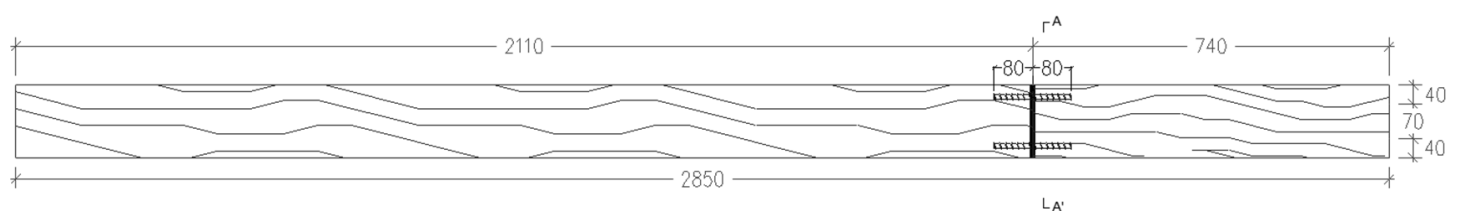

a) Vertical joint

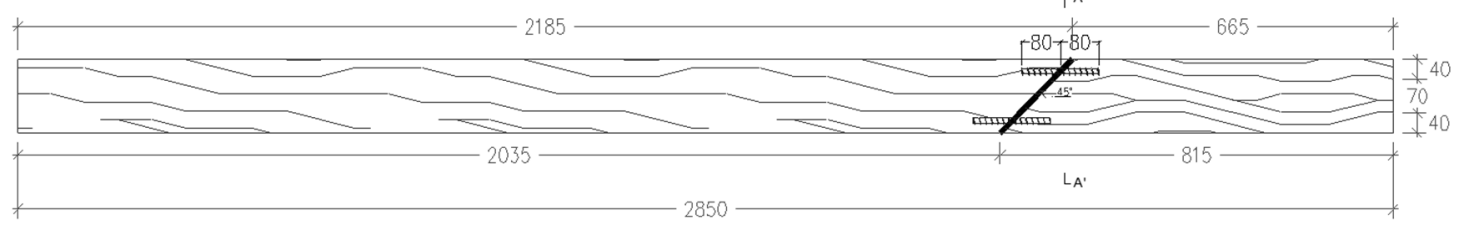

b) Diagonal joint

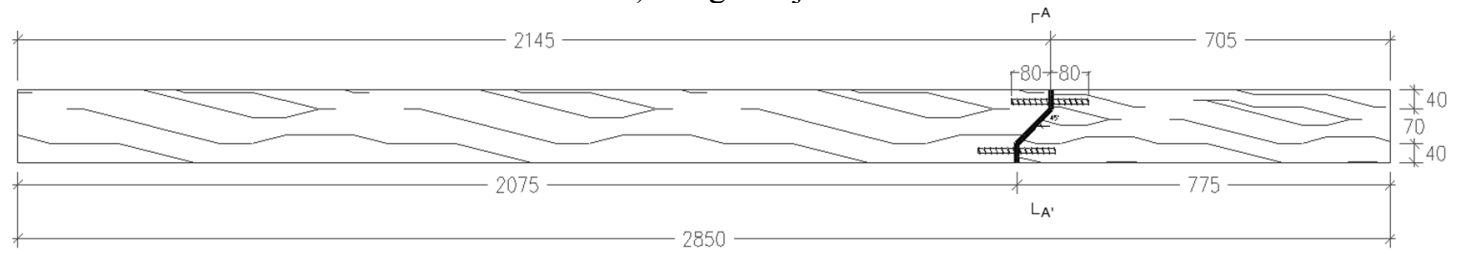

c) Mixed joint

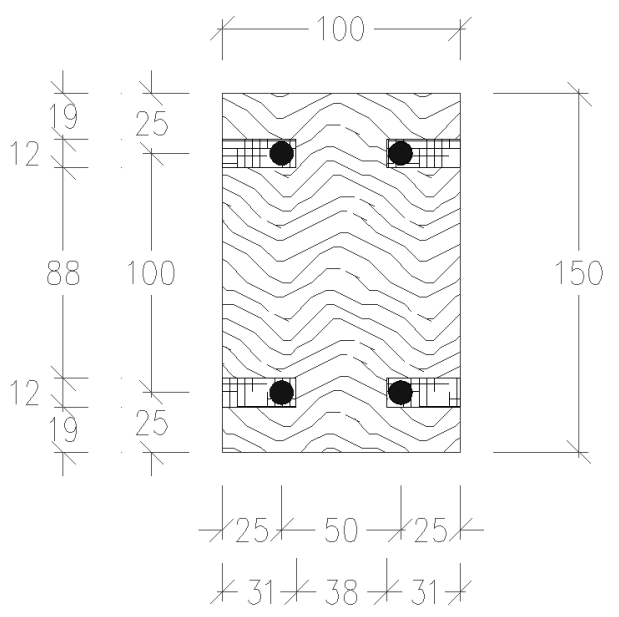

d) Detail A

Figure 3. Specimens representing the repair technique based on timber prosthesis (dimensions in millimeters). 


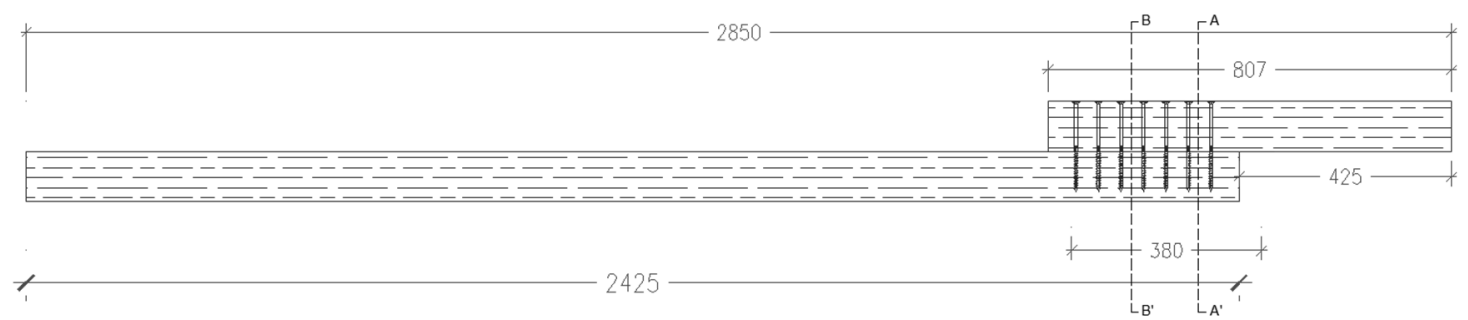

a) Plan view

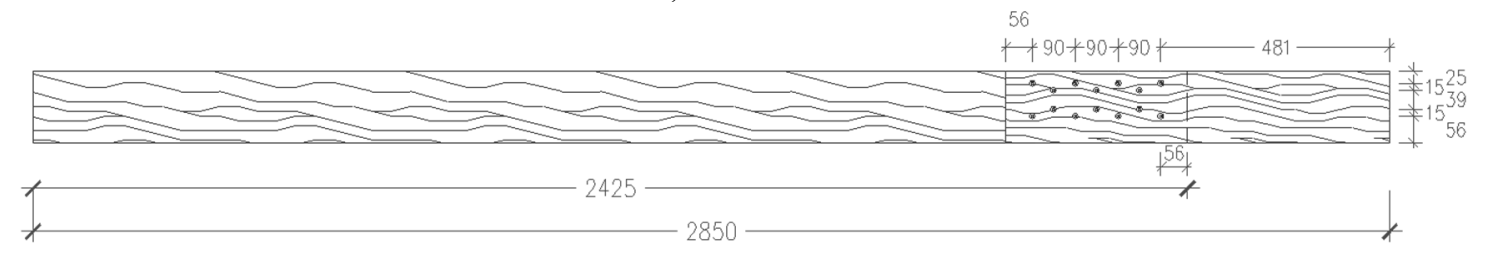

b) Lateral view

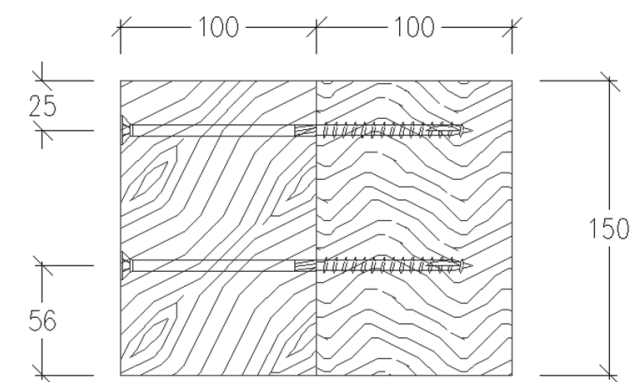

c) Detail A

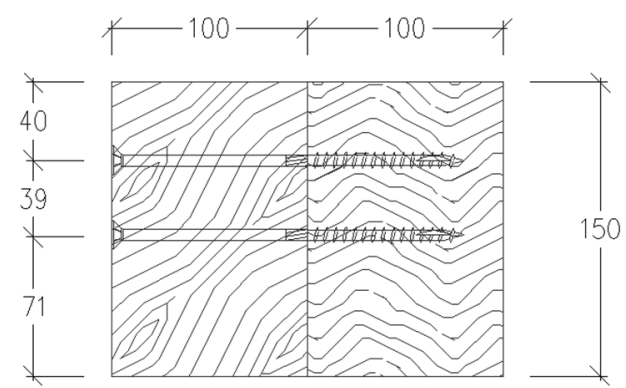

d) Detail B

Figure 4. Specimens representing the repair technique based on one new timber element (dimensions in millimeters).

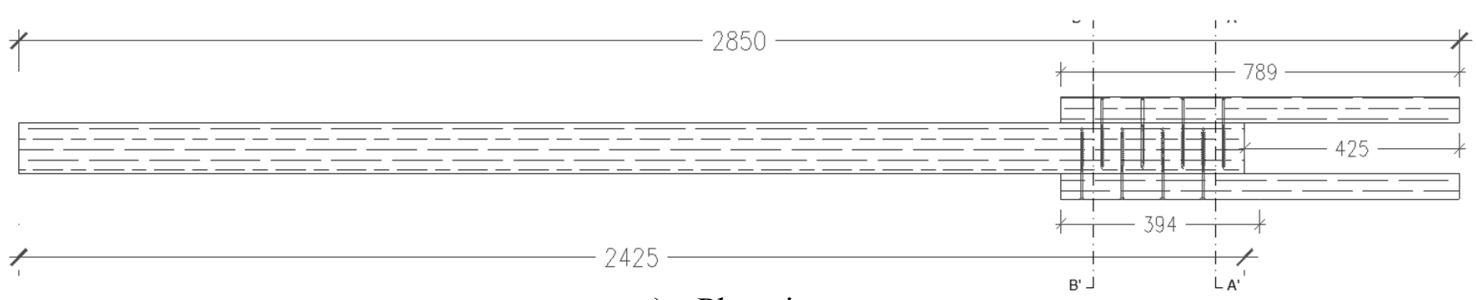

a) Plan view

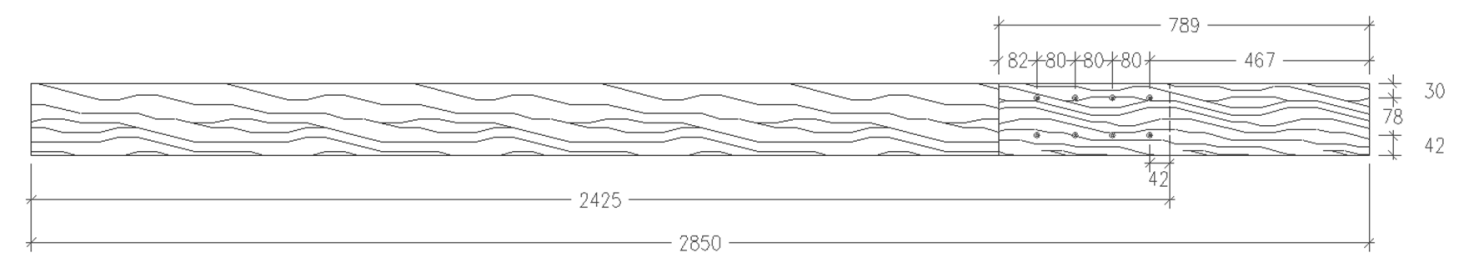

|

b) Lateral view

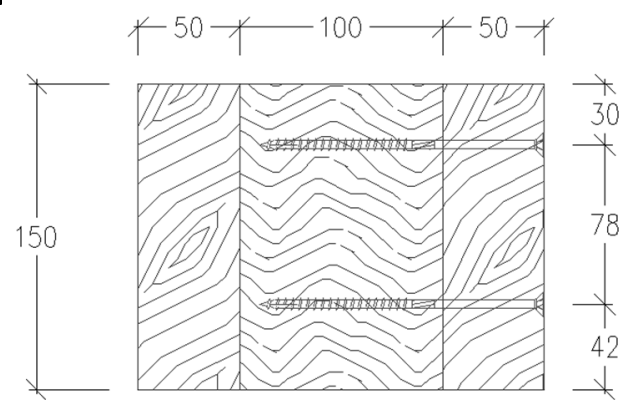

c) Detail A

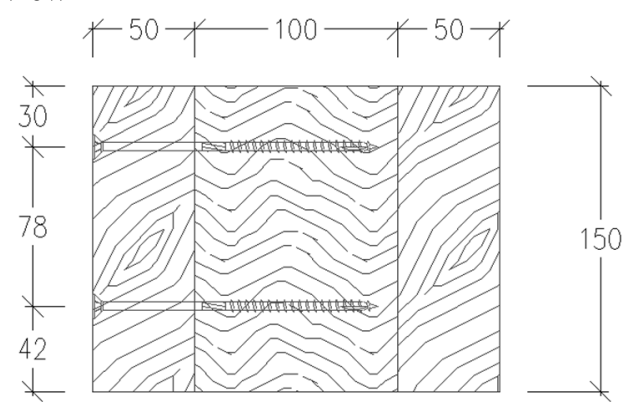

d) Detail B

Figure 5. Specimens representing the repair technique based on two new timber elements (dimensions in millimeters). 


\subsection{Specimens preparation}

All specimens have been built by AOF - Augusto de Oliveira Ferreira \& CA, Lda, in their own carpentry in Braga, applying the best practices developed more than 50 years of extensive field activity of intervention on existing timber structures. Specimens have been produced and after 10 days they have been transported to the Structural Laboratory of University of Minho in Guimarães. As example, Figure 6 shows the main steps in the production of the specimens used to evaluate the series GM.

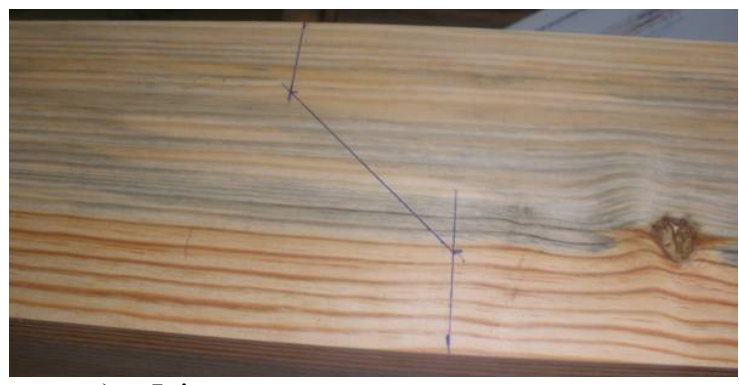

a) Joint geometry

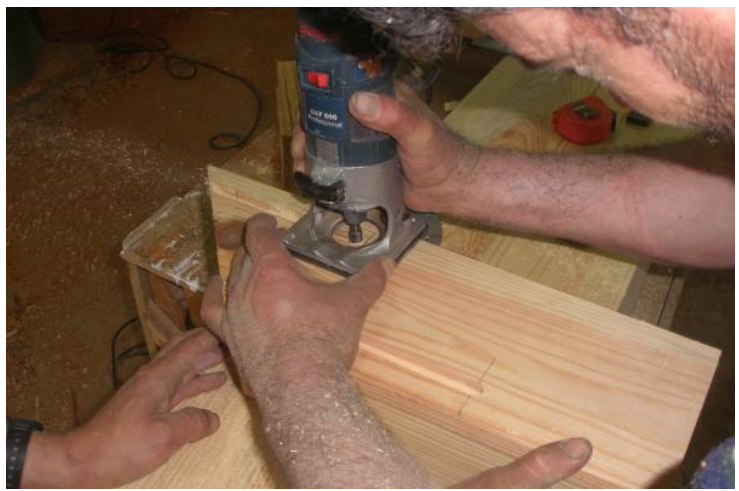

c) Grooves excution with a woodrouter

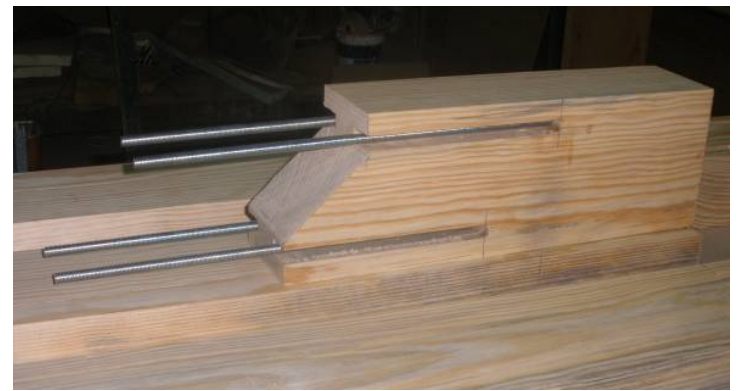

e) Position of the rods inside the grooves

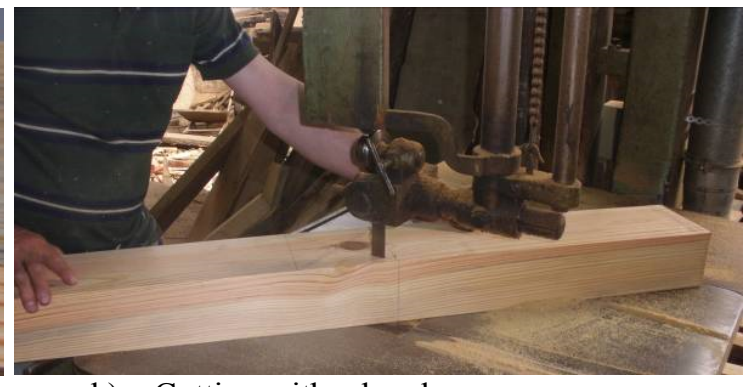

b) Cutting with a bandsaw

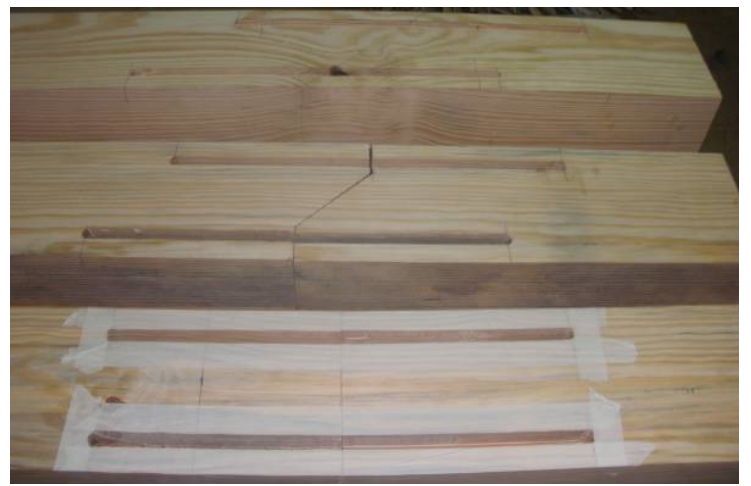

d) Cleaning and sealing of the grooves

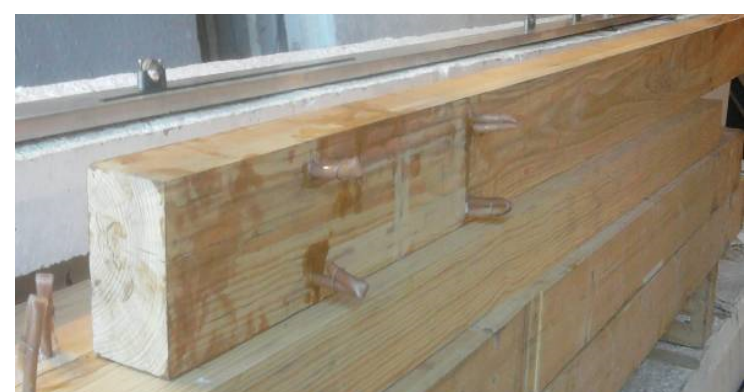

f) Curing of the glue

Figure 6. Main steps in the specimens repaired with timber prosthesis.

\subsection{Test setup and load procedure}

The four-point bending tests were conducted with reference to EN 408:2010. Those tests use a piece simply supported with a span of 18 times the depth with the loads points placed on the third of the span, as it is shown in Figure 7. The deformation at the mid-span was measured through one linear voltage displacement transducer (LVDT). 


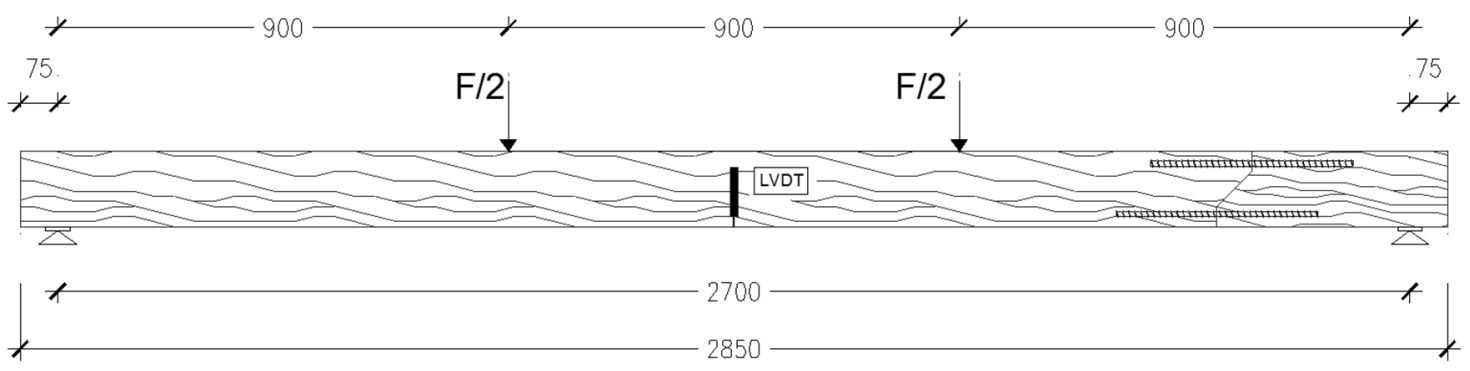

Figure 7. Test setup adopted (dimensions in millimeters).

Displacement control was used for the tests under a displacement rate of $0.15 \mathrm{~mm} / \mathrm{s}$. The load procedure adopted consisted in a recommended first load and unloading cycle after which the displacement was incremented until failure was achieved. The displacement rate adopted was defined in order that the maximum applied load was reached in $300 \pm 120 \mathrm{~s}$ after the load and unloading cycle. Figure 8 presents the load procedure adopted for all tests performed.

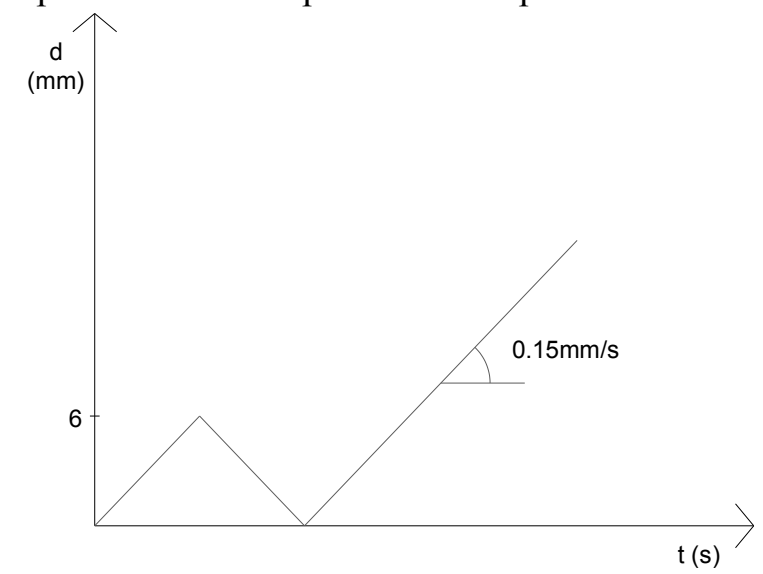

Figure 8. Load procedure adopted.

\subsection{Tests results}

Ina first approaches, the results of the tests performed are analyzed based in the maximum load value $\left(F_{\max }\right)$, the bending moment acting in the joint $\left(M_{\mathrm{j}}\right)$, the bending stress reached by the specimen in the zone of failure $\left(\sigma_{\mathrm{m}}\right)$ and the failure mode observed (Table 2$)$. Moreover, the experimental load-displacement curves registered are depicts in Figures 9 and 10.

Table 2. Main tests results obtained.

\begin{tabular}{|c|c|c|c|c|c|}
\hline Specimen & Technique & $F_{\max }(\mathrm{kN})$ & $M_{\mathrm{j}}(\mathrm{kNm})$ & $\sigma_{\mathrm{m}}(\mathrm{MPa})$ & Failure Mode \\
\hline $\mathrm{O} 1$ & \multirow{3}{*}{$\begin{array}{l}\text { One element screwed } \\
\text { in single shear }\end{array}$} & 28.21 & 4.02 & 10.72 & \multirow{3}{*}{ Wood splitting } \\
\hline $\mathrm{O} 2$ & & 26.57 & 3.97 & 10.60 & \\
\hline $\mathrm{O} 3$ & & 23.22 & 4.33 & 11.56 & \\
\hline $\mathrm{T} 1$ & \multirow{3}{*}{$\begin{array}{l}\text { Two elements screwed } \\
\text { in double shear }\end{array}$} & 15.32 & 7.41 & 19.75 & \multirow{3}{*}{ Joint rotation } \\
\hline $\mathrm{T} 2$ & & 15.13 & 6.97 & 18.60 & \\
\hline T3 & & 16.51 & 6.10 & 16.25 & \\
\hline GV1 & \multirow{3}{*}{$\begin{array}{l}\text { Glued-in steel rods } \\
\text { with a vertical joint }\end{array}$} & 20.60 & 7.62 & 18.30 & \multirow{3}{*}{ Rod withdrawn } \\
\hline GV2 & & 20.60 & 7.62 & 19.30 & \\
\hline GV3 & & 18.00 & 6.70 & 15.90 & \\
\hline GD1 & \multirow{3}{*}{$\begin{array}{l}\text { Glued-in steel rods } \\
\text { with a diagonal joint }\end{array}$} & 19.70 & 7.28 & 17.40 & \multirow{3}{*}{ Rod withdrawn } \\
\hline GD2 & & 28.30 & 10.47 & 25.10 & \\
\hline GD3 & & 24.00 & 8.90 & 21.40 & \\
\hline GM1 & \multirow{3}{*}{$\begin{array}{l}\text { Glued-in steel rods } \\
\text { with a mixed joint }\end{array}$} & 17.20 & 6.38 & 20.70 & Wood failure \\
\hline GM2 & & 14.80 & 5.47 & 13.10 & \multirow{2}{*}{ Rod withdrawn } \\
\hline GM3 & & 23.40 & 8.70 & 20.70 & \\
\hline
\end{tabular}



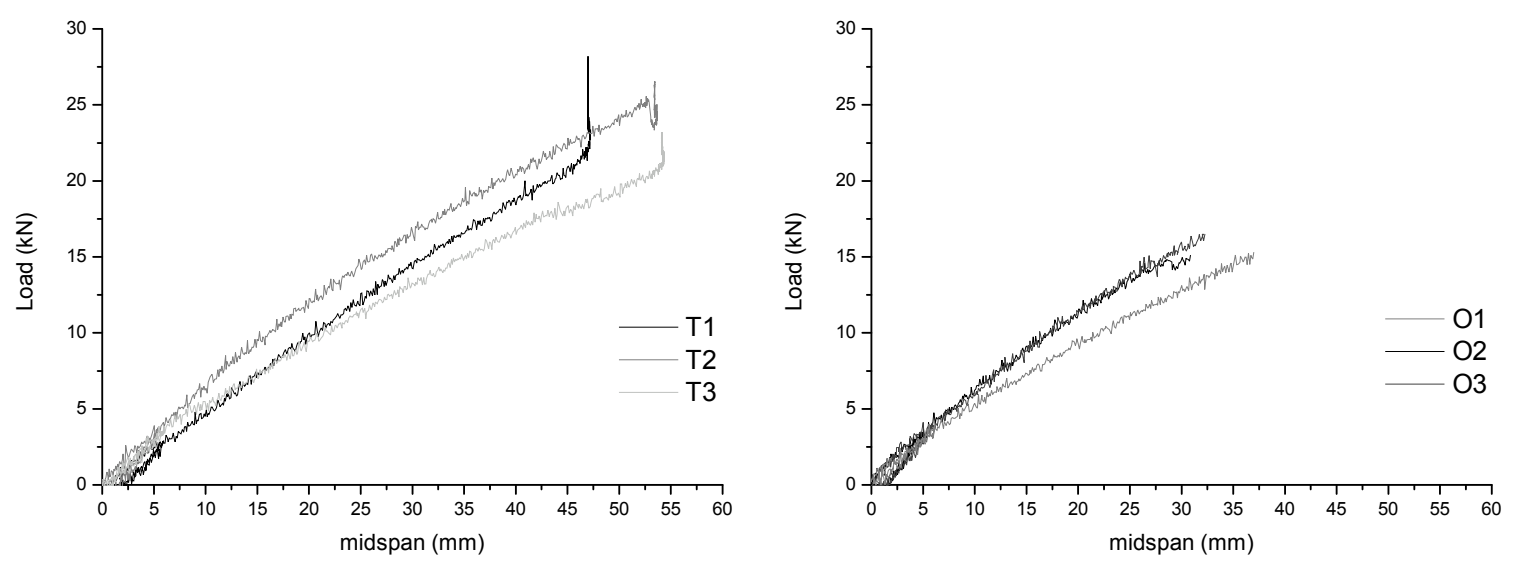

Figure 9. Experimental load-midspan displacement obtained for the series $\mathrm{O}$ and $\mathrm{T}$.
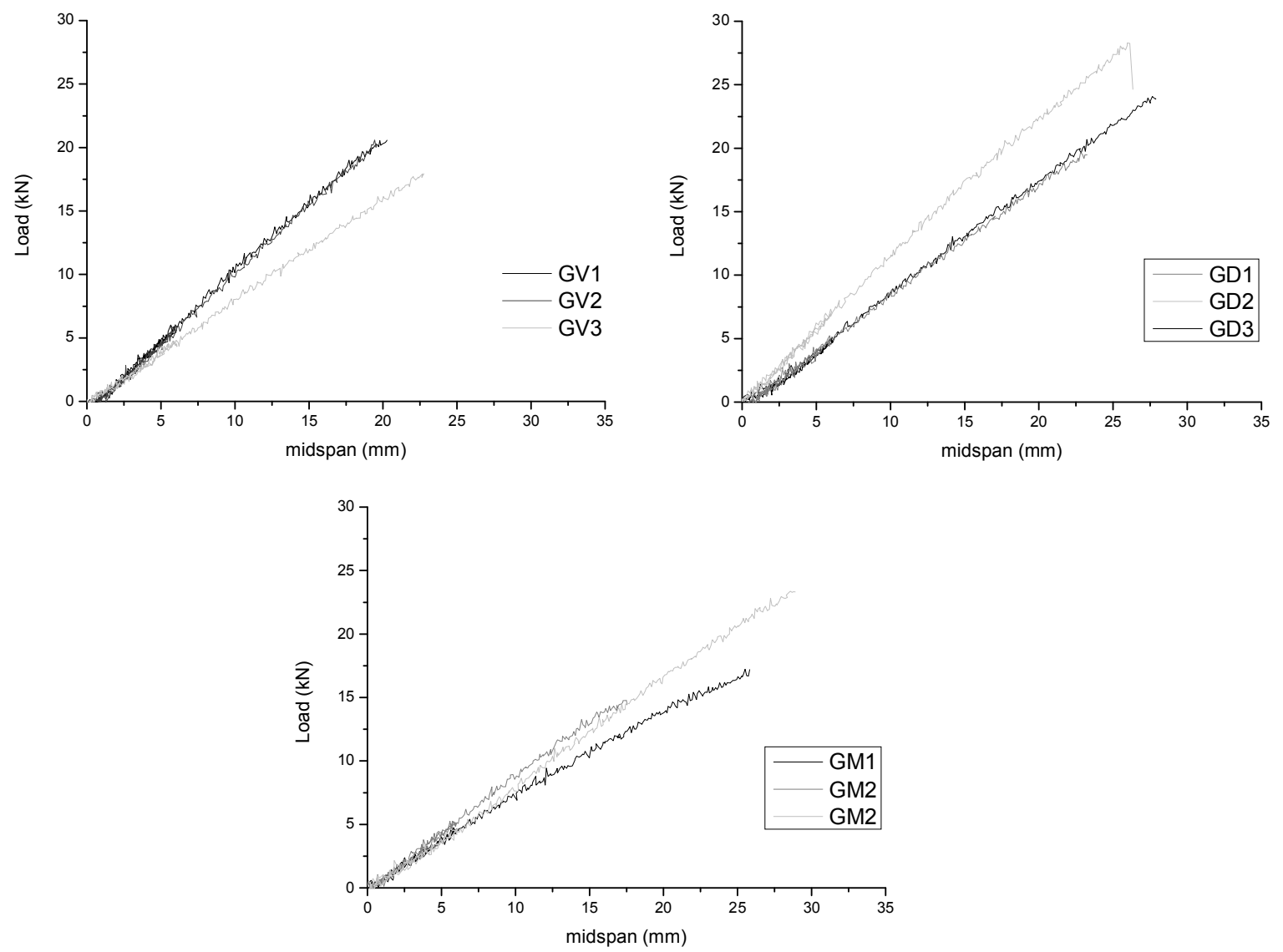

Figure 10. Experimental load-midspan displacement obtained for the series GV, GD and GM.

As general comment, it is possible to identify the good homogeneity demonstrated by the tests results in terms of $F_{\max }$, stiffness and failure mode within each series of specimens. The few deviation resulted from the presence of natural defects, namely the large knots characteristics from the maritime pine. Comparing the repairing techniques based in the use of new timber elements screwed to the original one, the specimens of series $\mathrm{T}$ with two new elements, presented lower values for $F_{\max }$, but the large deformation presented by the joint in this series, leading to a significant rotation of the joint, has limited the load-carrying capacity of the specimens. Between the series using timber prosthesis, the one with the diagonal joint has reached the higher values for $F_{\text {max. }}$ 


\subsection{Discussion}

The efficiency of the repairing techniques for decayed timber end beams based in the use of new timber elements screwed to the original, was limited. In fact, due to the large deformation demonstrated by the specimens tested within series $\mathrm{O}$ and $\mathrm{T}$, the load-carrying capacity of these specimens is inferior to the expected value. In particular, the joint of specimens of series Thave showed a behavior similar to a hinge (Figure 11b). In other hand, the specimens of series $\mathrm{O}$, with only one new timber element, have failed by wood splitting (Figure 11a) due to tension stresses perpendicular to the grain that occurred in the row of screws located in the tension side (below the neutral axis). Those stresses could be prevent by local reinforcements, but it is important to point out that the geometry of the cross-section selected, with a reduce height, promotes this kind of behavior.

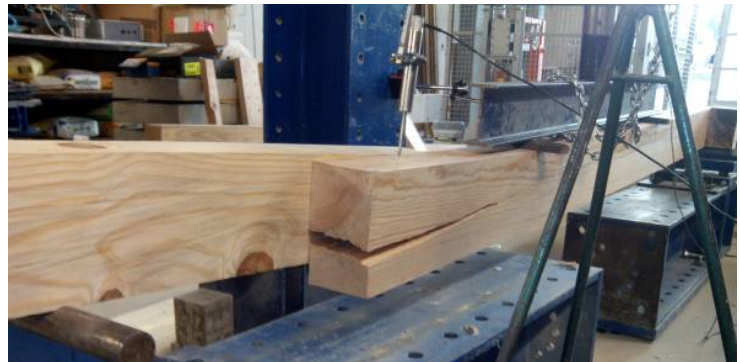

a) Wood splitting in series $\mathrm{O}$

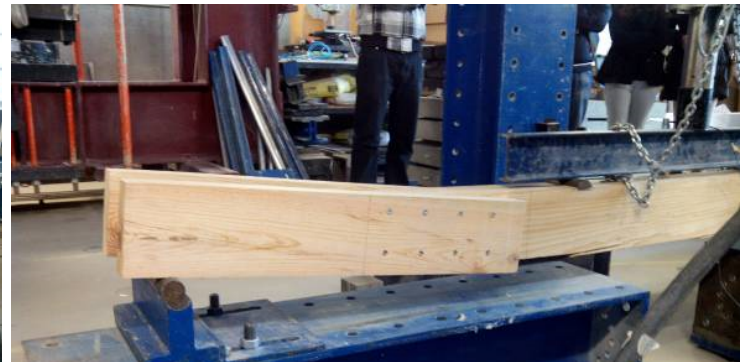

b) Rotation of the joint in series $\mathrm{T}$

Figure 11. Failures modes observed in specimens of series $\mathrm{O}$ and $\mathrm{T}$.

Analyzing the results obtained in the series defined to evaluate the possibility to use timber prosthesis connected by glued-in steel rods with different joints geometries, the behavior observed for this repairing technique is encouraging. First, the design method calibrated based in previous exploratory tests seems appropriate as it was possible to obtained in 8 of the 9 specimens tested, a failure in the joint by withdrawn of the steel rod (Figure 12). This failure could be easily avoid, with a direct improvement of the load-carrying capacity of the specimen, by increasing the anchorage length of the steel rod. However, the glued-in steel rods joint were design assuming the methodology purposed by (Pizzo et al., 2013) and calibrated through exploratory tests, assuming a maximum stress value of $18 \mathrm{MPa}$ corresponding to the strength class $\mathrm{C} 18$ defined by EN 1912:2004 for the maritime pine. In all cases, this value of the bending strength of the specimen was exceeded demonstrating the accuracy of the design method calibrated.

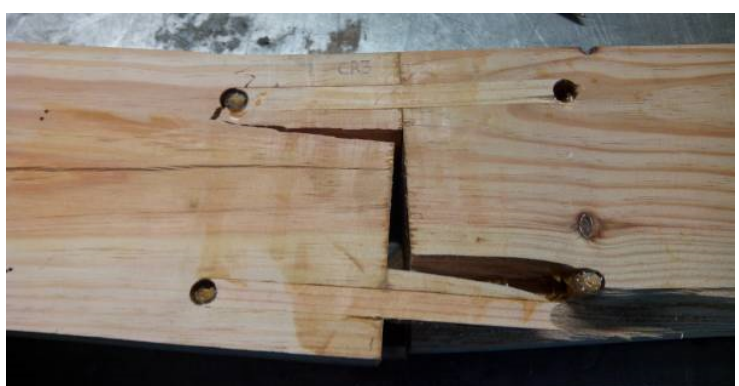

a) Series GV

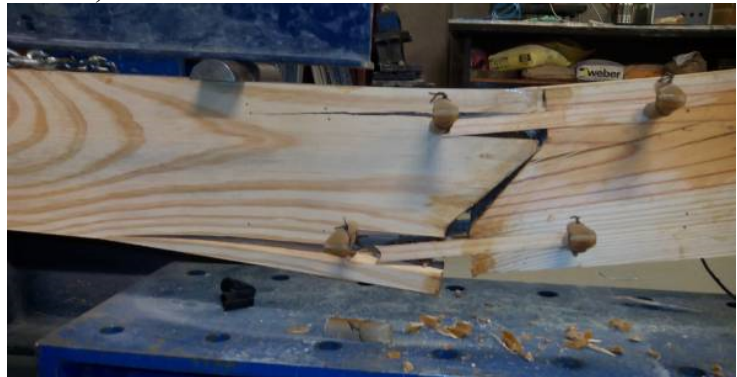

c) Series GM

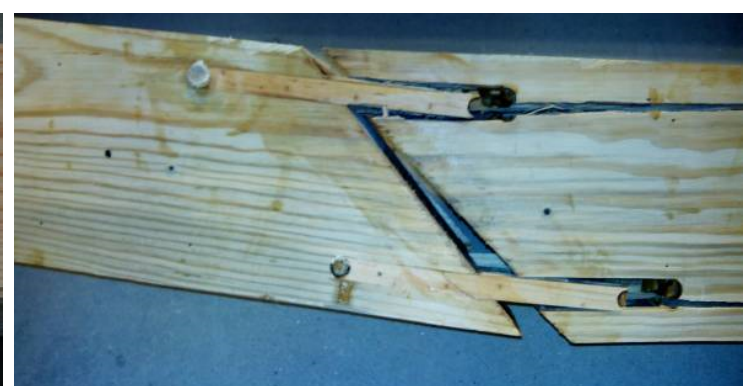

b) Series GD

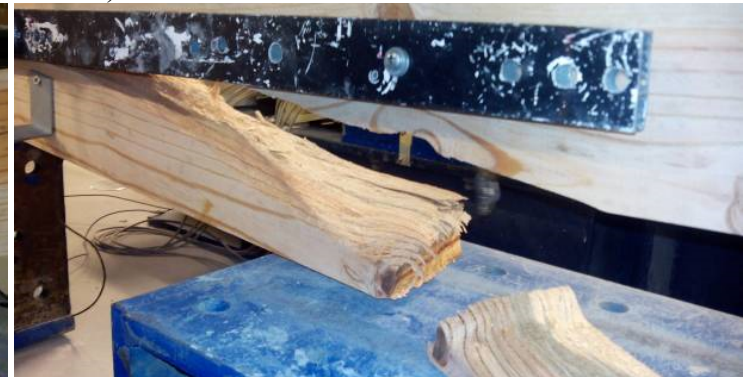

d) Wood failure of specimens GM1

Figure 12. Typical failures modes observed in specimens of series GV, GD and GM. 


\section{CONCLUSIONS}

This works explores the potentialities of using glued-in steel rods to connect timber prosthesis in the repairing of decayed timber end beams. For that purpose, an experimental campaign composed by four-point bending tests was defined. Exploratory tests were performed in a previous step to calibrate the design method to be used ensuring that the failure occurred in the joints. Based in those assumptions, the experimental campaign was successful has almost all the specimens failed in the joint by withdrawn of steel rods. Three series with timber prosthesis were considered, varying only the geometry of the joint (of the cut) between vertical, diagonal and mixed. Tests results have demonstrated that the specimens with diagonal joints behave better.

For comparison purposes, two series of specimens repaired with new timber elements screwed to the original beam have been also considered. When one new element is used, the screws were placed in single shear and in double shear when two new timber elements were employed. The efficiency of those repair techniques was limited by the small cross-section adopted for the specimens. In fact, this reduced height of the beams hindered the effectiveness of the screwed connection between the new element and the original one. Wood splitting due to tension perpendicular to the grain and significant rotation in the joint, have been observed in the specimens of those series.

In sum, the experimental campaign reported here demonstrated the efficiency of the use of timber prosthesis connected to the original element by glued-in steel rods in the repair of damaged timber end beams. The intervention can be low, using small lengths of rods ( 8 times the diameter) and engaging a small quantity of glue. The technique used for the placement of the glued-in steel rods was defined and developed requiring its easy execution on-site.

\section{ACKNOWLEDGEMENTS}

The present work is part of a research project supported by program Quadro de Referência Estratégico Nacional (QREN) from the Agência de Inovação (ADI) through the project Vale Inovação REPAR - Desenvolvimento de um sistema integrado de reforço alternativo para construções históricas.

\section{REFERENCES}

Appleton, J. 2003. Reabilitação de edifícios antigos. Patologias e tecnologias da intervenção. Orion, Lisboa, Portugal. (in Portuguese).

Arriaga, F., Peraza, F., Esteban, M., Bobadila, I. \& Garcia, F. 2002. Intervención en estructuras de madera. AITIM , Espanha: 512 pp.

Barbaro, D. 1997. I dieci libri dell'architettura di M. Vitruvio (anastatic printing from the original of 1567). Milano: Il Polifilo.

CNR-DT 206/2007. Istruzioni per la Progettazione, l'Esecuzione ed il Controllo di Strutture di Legno. Consiglio Nazionale delle Ricerche, Roma.

EN 338:2003. Structural timber: strength classes. European Committee for Standardization, Brussels.

EN 408:2010. Timber structures - Structural timber and glued laminated timber - Determination of some physical and mechanical properties, European Committee for Standardization. Brussels.

EN 1912:2004. Structural timber - Strength classes - Assignment of visual grades and species. European Committee for Standardization, Brussels.

EN 1995-1-1:2004. Eurocode 5. Design of timber structures. Part 1-1: General - Common rules and rules for buildings. European Committee for Standardization, Brussels.

EN 1995-2:2008. Eurocode 5: design of timber structures. Part 2: Bridges. European Committee for Standardization, Brussels.

ENV 1995-2:1997. Eurocode 5: design of timber structures. Part 2: Bridges. European Committee for Standardization, Brussels.

ICOMOS International Wood Committee 2003. Principles for the Preservation of Historic Timber Buildings. 14th Symposium in Patzcuaro Michoacan, Mexico November 10-14 2003.

NP 4305:1995. Madeira serrada de pinheiro bravo para estruturas. CT 14, LNEC, Lisboa.

Portoghesi, P., Orlandi, G. \& Alberti, L.B. 1966. De re aedificatoria. Milano: Il Polifilo.

Pizzo, B., Gavioli, M. \& Lauriola, M.P. 2013. Evaluation of a design approach to the on-site structural repair of decayed old timber end beams. Engineering Structures, 48, 611-622.

Tampone, G. 1996. Il restauro delle strutture di legno. Ulrico Hoepli, Milan, Italy. 